\title{
ALFABETIZAÇÃO E ÉTICA: UM TRABALHO INTERDISCIPLINAR DE FORMAÇÃO DOCENTE E DISCENTE
}

\author{
LITERACY AND ETHICS: A INTERDISCIPLINARY WORK OF TEACHERS AND \\ STUDENTS TRAINING
}

Ana Lúzia Magalhães Carneiro ${ }^{1}$

\begin{abstract}
RESUMO: O trabalho sobre a temática da Ética proposto pelos Parâmetros Curriculares Nacionais (1997) é essencial para o desenvolvimento da autonomia de crianças e adolescentes. Entretanto, as dificuldades de aprendizagem principalmente no sistema público de educação, impõem práticas educativas focadas na leitura, escrita e cálculos básicos, em detrimento dos problemas da realidade das comunidades escolares. Quando as escolas decidem desenvolver projetos sobre as relações de desrespeito e o tipo de imagem que as crianças constroem de si e do "outro", a área de História passa a assumir o trabalho de formação. Este artigo pretende discutir uma experiência vivenciada por professores e alunos dos anos iniciais do Ensino Fundamental, na qual a alfabetização e a ética constituíram-se como eixos para o desenvolvimento de um projeto de formação/ação docente e discente.
\end{abstract}

Palavras-chaves: Alfabetização e ética. Projeto especial de ação. Formação docente e discente. Práticas interdisciplinares.

\begin{abstract}
Working about the theme of Ethics proposed by the National Curriculum Standards (1997) is essential for the development of autonomy of children and adolescents. However, learning difficulties especially in the public education system, impose educational practices focused on reading, writing and basic calculations at the expense of the reality of the problems of school communities. When schools decide to develop projects on the relations of disrespect and the type of image that children build themselves and the "other", the History area now takes on the job training. This paper discusses an experience lived by teachers and students of the early years of elementary school, in which literacy and ethics were constituted as axes for the development of a project training/teaching activities and students.
\end{abstract}

Keywords: Literacy and ethics. Special design of action. Teacher training and student. Interdisciplinary practices.

\footnotetext{
${ }^{1}$ Doutora em Educação pela Pontifícia Universidade Católica de São Paulo. Docente Adjunta do Centro Universitário São Camilo de São Paulo. Coordenadora Pedagógica da Secretaria de Educação Municipal de São Paulo.
} 


\section{Introdução}

Neste artigo pretende-se apresentar um projeto desenvolvido em uma escola da zona oeste da cidade de São Paulo, durante os anos de 2013 e 2014, por professores e coordenação com Jornada de Trabalho Especial de Formação Integral - JEIF, denominado Projeto Especial de Ação- PEA, com periodicidade de dois encontros semanais ao longo de cada ano, totalizando 146 horas anuais de atividades formativas, que culminaram no desenvolvimento de práticas pedagógicas diferenciadas para alunos dos anos iniciais do ensino fundamental.

O desenvolvimento deste projeto denominado "Alfabetização e Ética na escola: autonomia discente, autoridade docente e mediação de conflitos" foi implementado quando verificamos que outros problemas, como a violência, a participação da família na escola, a inclusão, o bullying, as relações de poder entre professores, alunos e comunidade permeavam o processo de ensino e aprendizagem, interferindo de forma direta nas metodologias de aula e na consequente aprendizagem em relação à leitura, escrita e o conhecimento matemático. Nos três anos anteriores, o foco deste projeto foi "Alfabetização e Letramento matemático", mas em 2013 constatamos que esta discussão deveria ser ampliada, na medida em que percebíamos que os problemas sociais estavam cada vez mais presentes nas salas de aula.

Em 2014, ao iniciarmos as pesquisas para elaboração do projeto, nos deparamos com uma extensa bibliografia sobre as diferentes formas de violência escolar, a mediação dos conflitos, a exclusão social e a intrínseca relação destas questões com a concepção ética que professores, alunos e comunidade vivenciam no cotidiano da escola. Partimos de uma reflexão proposta por Aquino (2000: p. 32) para definirmos o tema e os caminhos de formação que adotaríamos para o projeto:

É certo que competência teórica e técnica é uma condição mesma do próprio jogo pedagógico. Contudo, aquilo que conotamos usualmente como "acidentes de percurso" requer, mais do que uma revisão metodológica e/ou teórica, uma interpelação ética: o que precisa ser preservado em minha ação? Afinal de contas, a que ela se presta? Que mundo se vislumbra aqui e agora? Perguntas ao mesmo tempo sutis e intrincadas, mas intransferíveis, posto que conclamam a ética pedagógica, e tão 
somente ela, como reguladora da ação escolar. Que resposta cada um de nós poderia dar a essas questões?

Responder estas questões tornou-se um desafio para o grupo e, somente no decorrer do projeto, fomos adquirindo consciência de que não conseguiríamos respondê-las, se não nos debruçássemos sobre o desvelamento da prática pedagógica à luz do conhecimento histórico, das pesquisas e produções teóricas que abordam a autonomia discente, a autoridade docente, as relações de poder e a mediação de conflitos na relação entre as concepções éticas e o trabalho de alfabetização na escola.

Acreditamos que a realização deste projeto nos faria ter maior clareza sobre o papel e a importância da escola na vida de crianças e jovens de nossa comunidade, sendo, muitas vezes, o único espaço em que podem ter contato com a produção cultural, e com o trabalho intelectual promovido pelas diversas áreas do conhecimento. Ao mesmo tempo, poderíamos vivenciar com nossos alunos a construção das relações sociais a partir de um melhor entendimento dos conflitos provenientes, principalmente, da não aceitação das diferenças e da diversidade, seja étnico-racial, sexual, cultural ou social.

Estas constatações nos levaram a propor que o projeto se tornasse um espaço para estudos interdisciplinares e análises sobre os diferentes tipos de problemas que cercam muitos alunos e interferem em seu processo de aprendizagem, na sua visão de mundo e na relação que estabelecem com o "outro". Além disso, o trabalho com a diversidade cultural, social e étnico-racial, as formas de violência e exclusão, eram metas estabelecidas no Projeto Pedagógico da escola.

Dessa forma, o desenvolvimento do projeto, além de auxiliar no cumprimento das metas propostas no Projeto Político Pedagógico, deveria aprimorar a fundamentação teórica dos professores sobre sua concepção de educação, de escola e de vida; para desenvolver diferentes metodologias que privilegiassem a construção de um espaço mais democrático e participativo, sem deixar de pesquisar, estudar e intervir nas relações ético-sociais que se desenvolvem dentro e fora da escola.

Para tanto foram estabelecidos os seguintes objetivos: 
- Promover a formação continuada dos professores para organizarem situações didáticas que favoreçam a relação ensino-aprendizagem nos parâmetros da ética escolar e da perspectiva da inclusão;

- Analisar as relações sociais da comunidade escolar, privilegiando o debate sobre a diversidade étnico-racial, as formas de violência contra o outro e a inclusão;

- Estudar documentos referentes à mediação de conflitos e à violência, adequando-os às necessidades da escola;

- Subsidiar reflexão da equipe docente sobre situações de conflitos para melhoria do convívio escolar;

- Conhecer os princípios éticos de um ambiente de trabalho a partir da relação dialógica, cooperativa e da perspectiva inclusiva;

- Orientar a elaboração de planos de trabalho e projetos voltados para a construção da ética pedagógica, da autonomia discente e da inclusão.

\section{Caracterização da realidade escolar como fundamentação para o desenvolvimento do projeto:}

Em 2014, a unidade escolar em questão contava com 1.137 (Mil, cento e trinta e sete) alunos matriculados, dos quais 483 (quatrocentos e oitenta e três) eram dos anos iniciais do ensino fundamental, 371 (trezentos e setenta e um) dos anos finais e 283 (duzentos e oitenta e três) eram alunos da Educação de Jovens e Adultos. Do total de 1.137, tínhamos 545 (quinhentos e quarenta cinco) alunos do sexo masculino e 592 (quinhentos e noventa e dois) alunos do sexo feminino.

No início do ano letivo, aplicamos um questionário à comunidade escolar com o objetivo de obter informações mais precisas sobre o perfil socioeconômico e cultural das famílias de nossos alunos. A aplicação ocorreu durante os dias em que foram entregues os uniformes escolares e contamos com o preenchimento de 706 questionários por pais/responsáveis (ou representantes) dos alunos do ensino fundamental dos períodos matutino e vespertino. Se considerarmos que em 2014 tínhamos um total de 854 alunos matriculados nos dois turnos, nossa 
amostra foi de $82,66 \%$, indicando uma representatividade substancial e significativa para os objetivos propostos.

A tabulação destes questionários possibilitou identificar que $23 \%$ das famílias apresentavam problemas familiares ocasionados por fatores de ordens socioeconômica e cultural, como a pobreza extremada, falta de emprego formal, falta de serviços essenciais de qualidade, falta de acesso à cultura e ao lazer, entre outros aspectos, que ultrapassam os limites da escola. Identificamos também, que $43 \%$ das famílias possuíam renda familiar entre um e dois salários mínimos, enquanto $23 \%$ encontravam-se na faixa de dois a três salários e, $11 \%$ viviam com renda acima de quatro salários, o que indica que a maioria das famílias da nossa comunidade está inserida na "nova classe média". Segundo critérios da pesquisa realizada pela Fundação Getúlio Vargas:

\begin{abstract}
A "nova classe média", ou "nova classe C", está compreendida abaixo da A e B e acima da D e E. A fim de quantificar a renda, foi realizado um cálculo da renda per capita de cada domicílio. Dessa forma, a classe $C$ tem uma renda entre $R \$ 1.064,00$ e $R \$ 4.561,00$ e se localiza acima dos $50 \%$ mais pobres e abaixo dos $10 \%$ mais ricos do país. A chamada "nova classe média" brasileira - a classe C - refere-se a $52,67 \%$ da população, o equivalente a quase 98 milhões de pessoas. Dessa forma, o economista Marcelo Neri (2008, p. 5) aponta que a classe $C$ "é a imagem mais próxima da sociedade brasileira". (YACCOUB, 2011)
\end{abstract}

\title{
Entretanto para o sociólogo Jessé de Souza
}

[...] Esse conceito de classe média, que tudo abrange, serve apenas para encobrir conflitos e injustiças sociais de todo tipo. Para essa versão dominante: 'classe média' é apenas um amontoado de 'indivíduos' que competem em igualdade de condições pelos recursos sociais escassos. (Nova classe média, 2013).

É a partir deste conceito que verificamos que, apesar de termos mudanças no perfil econômico de nossa comunidade, ainda há carências sociais, culturais e econômicas para muitos alunos. Este quadro pode ser percebido quando identificamos que $39 \%$ dos participantes da pesquisa disseram que assistir à TV é a principal ocupação que tem em seu tempo livre, enquanto $23 \%$ realizavam passeios com a família, $20 \%$ indicaram a leitura de livros, jornais e revistas como ocupação do tempo e, apenas 7\% afirmaram ir ao cinema. Quanto ao 
acesso às redes de comunicação, 39\% utilizavam a internet diariamente e 31\% utilizavam às vezes, entretanto, $30 \%$ tinham acesso restrito ou bastante esporádico.

Entendemos que estas carências exercem interferências no desenvolvimento da aprendizagem e das relações sociais estabelecidas no âmbito da escola. Constatamos as mudanças econômicas no bairro, mas também verificamos que a partir de 2013 houve um aumento nos conflitos escolares, provocados pela diferenciação de tipos e locais de moradia, além das diferenças de acesso ao consumo de vestuário e acessórios como camisetas, calças, bonés, bolsas, mochilas, tênis, etc. e, de produtos eletrônicos como os aparelhos de celular. Não podemos desprezar a influência do movimento musical relacionado ao "funk ostentação" que tem crianças e adolescentes das periferias como principais alvos e, por isso, durante os anos de 2013 e 2014, alteramos a abrangência do projeto para focar as relações entre o trabalho de alfabetização e a ética, a partir das concepções de autonomia discente, autoridade docente e mediação de conflitos.

Tais aspectos foram ratificados no fechamento do ano letivo de 2013, que teve um alto número de ocorrências de conflitos entre alunos, totalizando 120 registros, somente entre alunos dos anos iniciais, sendo que grande parte ocorreu fora da sala de aula, porque durante a aula, havia a intermediação do professor. Estas constatações, juntamente com o levantamento de casos de alunos faltosos e que apresentavam sinais de negligência familiar, foram alguns aspectos que consideramos relevantes para iniciarmos um trabalho com o foco na convivência escolar, nas relações entre indisciplina e aprendizagem.

Outra constatação de que a melhoria econômica por si só não resolve os problemas relacionados às crianças e jovens, foi o visível crescimento de adolescentes envolvidos com entorpecentes entre os anos de 2013 e 2014, verificado pelo número de atendimentos realizados às famílias, indicando a falta de perspectiva de vida futura, ausência de programas e projetos sociais voltados para o lazer e cultura nesta comunidade.

Sabíamos que para alcançar os objetivos propostos no Projeto e os resultados esperados, seria necessário voltarmos o olhar para as práticas desenvolvidas em sala de aula e as relações existentes entre a equipe escolar e 
os alunos, a qualidade da intermediação exercida por professores, equipe gestora e funcionários dentro e fora das salas de aula.

Neste sentido tornou-se necessário resgatar os princípios éticos propostos no documento Temas Transversais: Ética (1997), aprofundar os conhecimentos teóricos, refletir sobre a prática pedagógica e desenvolver estratégias diferenciadas, visando o aprimoramento do trabalho realizado dentro e fora de sala de aula, o diálogo, a ressignificação do conceito de autoridade docente e a busca pela autonomia discente, como processos norteadores para um convívio escolar pautado no binômio alfabetização e ética na escola.

Contudo, a pesquisa realizada nos forneceu indicadores interessantes e diferenciados da percepção que tínhamos da comunidade, como o nível de formação dos pais/ou responsáveis, já que $41 \%$ dos pesquisados informaram possuir o Ensino Médio completo; 14\% ensino médio incompleto; $11 \%$ ensino fundamental completo; $24 \%$ ensino fundamental incompleto. Apesar de apenas $1 \%$ informar que possuía formação superior completa, $9 \%$ dos pesquisados indicaram estar cursando esta etapa da educação.

Podemos inferir que os índices apontados acima demonstraram que pelo menos metade dos responsáveis pelos alunos tem mais condições para acompanhar a vida escolar e dar mais importância para esta etapa da vida, ainda que o interesse maior em relação à formação escolar esteja voltado para que os filhos tenham um melhor futuro no mercado de trabalho, aspecto apontado por $54 \%$ dos pesquisados, enquanto $41 \%$ acreditam na influência da educação para que os filhos se tornem cidadãos conscientes de seus direitos e deveres na sociedade.

Outra análise que estes dados nos permitiram fazer, diz respeito diretamente à Educação de Jovens e Adultos, já que apenas 24\% dos pais ou responsáveis informaram não possuir o ensino fundamental completo, o que explica a diminuição da procura por esta modalidade de ensino, não apenas em nossa unidade educacional, mas na região como um todo, principalmente nas Etapas de Alfabetização e Básica.

Alguns dados da pesquisa foram de extrema importância para a discussão curricular e o desenvolvimento de projetos da escola relacionados à diversidade étnico-racial, porque $34 \%$ dos pesquisados se declararam de origem 
afrodescendente, $32 \%$ se declararam brancos, $27 \%$ não informaram, $6 \%$ se declararam indígena e $1 \%$ de origem asiática. Entendemos que será necessário investigar com mais profundidade o que estes números podem representar em relação aos problemas que muitos alunos afrodescendentes enfrentam no cotidiano escolar, já que $27 \%$ dos pesquisados não quiseram ou não souberam se declarar quanto à cor. Diante deste quadro, verificamos que a realização de pesquisas qualitativas deverá ser feita para auxiliar no desenvolvimento de trabalhos pedagógicos sobre o posicionamento e comportamento social de nossa comunidade em relação à sua identidade e imagem.

A concepção de família nuclear, numerosa e de origem majoritariamente nordestina que predominava no imaginário dos profissionais da educação foi colocada em xeque pelos percentuais apresentados nos itens sobre estado civil, número de filhos e local de origem, demostrando que as mudanças sociais são rápidas e que não podemos nos fundamentar em estereótipos ou concepções pré-estabelecidas.

Os resultados destes itens comprovam tal assertiva já que $41 \%$ dos pesquisados se declararam solteiros/as; $88 \%$ declararam ter filhos e, deste total, $28 \%$ informaram ter mais de 1 filho, 24\% apontaram ter mais de 2 filhos, $20 \%$ mais de 3 filhos e $16 \%$ mais de 3 filhos. Ainda, na pesquisa, 59\% apresentaram a região sudeste como região de origem.

Vale ressaltar que os resultados também apontam para um quadro de composição familiar marcado pela presença religiosa, já que $25 \%$ dos pesquisados apontaram ir à igreja como um dos pontos que mais valorizam fazer junto com a família, mas a maioria, ou seja, 39\% apontou a realização de pelo menos uma refeição como a principal atividade para ser realizada em família.

Estes dados questionam os discursos de alguns profissionais da educação quando afirmam, por exemplo, "que as mães só colocam filhos no mundo e deixam para a escola criar", "que a maioria dos pais veio do Nordeste à procura de uma condição melhor de vida", "que as famílias devem ser constituídas por meio do casamento entre homem e mulher", entre muitas outras considerações que diante da realidade apresentada perdem força e fundamentação.

No questionário aplicado constavam questões sobre a percepção dos pais/responsáveis sobre a relação dos filhos com a escola e dos mesmos quanto 
à importância dada ao acompanhamento da vida escolar. Os resultados apontaram para uma grande valorização da escola perante a comunidade, já que 99\% responderam ser importante sua participação nas reuniões de pais; $98 \%$ informaram que buscam saber o que o filho aprende ao longo do ano; $98 \%$ veem a escola como importante para a família; $95 \%$ acreditam que a escola valoriza seus filhos e $95 \%$ afirmam que os filhos gostam da escola.

Entretanto, é possível perceber algumas contradições quando, somente a metade dos pesquisados, ou seja, 49\% afirmam ter participado de todas as reuniões de pais; $26 \%$ participaram de 3 reuniões, 16\% participaram de 2 reuniões e $9 \%$ de apenas uma reunião. Além disso, 52\% responderam que se pudessem colocariam o filho em escola particular e $48 \%$ informaram que não colocariam, mesmo que pudessem.

Estes dados reforçaram a decisão de rever o Currículo das áreas de conhecimento, principalmente, a área de História, para planejar ações condizentes com este perfil encontrado e, ao mesmo tempo, centrar o trabalho pedagógico no processo de pesquisa sobre aspectos referentes aos vários grupos de convívio dos alunos (familiares, étnico-culturais, profissionais, escolares, de vizinhança, religiosos, recreativos, artísticos, esportivos, políticos e etc.) a partir dos marcadores como sujeitos, tempo e fatos históricos.

\section{Práticas pedagógicas interdisciplinares}

Uma das ações de formação docente prevista para o início do projeto foi o estudo sobre a relação entre as concepções éticas e o trabalho pedagógico proposta no livro "Do cotidiano escolar: ensaios sobre a ética e seus avessos" (AQUINO, 2000) e no documento Temas Transversais: Ética (BRASIL, 1997), destacando-se o papel da escola na formação moral e intelectual das crianças e adolescentes como premissa para o desenvolvimento de uma educação de qualidade, colocando em debate os pressupostos de que a escola tem apenas a função de trabalhar os conhecimentos socialmente produzidos pela humanidade. Assim, houve concordância, se não de todos os participantes do projeto, mas de uma maioria de que 
A escola deve ser um lugar onde cada aluno encontre a possibilidade de se instrumentalizar para a realização de seus projetos; por isso, a qualidade do ensino é condição necessária à formação moral de seus alunos. Se não promove um ensino de boa qualidade, a escola condena seus alunos a sérias dificuldades futuras na vida e, decorrentemente, a que vejam seus projetos de vida frustrados. Ao lado do trabalho de ensino, o convívio dentro da escola deve ser organizado de maneira que os conceitos de justiça, respeito e solidariedade sejam vivificados e compreendidos pelos alunos como aliados à perspectiva de uma "vida boa". Dessa forma, não somente os alunos perceberão que esses valores e as regras decorrentes são coerentes com seus projetos de felicidade como serão integrados às suas personalidades: se respeitarão pelo fato de respeitá-los. (BRASIL, 1997: p. 55)

Um aspecto que precisa ser esclarecido diz respeito à relação entre os conceitos ética e moral, explicada pela associação com valores, princípios, normas e regras das relações sociais. Porém, a partir de leituras realizadas no grupo de formação, entendemos a ética como a reflexão que podemos realizar sobre o conjunto de valores que priorizamos, defendemos e trabalhamos com nossos alunos.

[...] Mas o fato de essas palavras poderem nos remeter a questões distintas (normas, fundamentos, estudos empíricos, vida boa) não deve passar despercebido. Há muita riqueza neste campo de reflexão, notadamente para a educação: trata-se de normatizar as condutas dos alunos? De instruí-los sobre sistemas éticos? De fazê-los refletir sobre as relações humanas? Sobre a felicidade? Sobre as virtudes? O tema "ética e educação" pode muito bem referir-se a essas perguntas e a outras ainda. (TAILLE; SOUZA; VIZIOLI, 2004: p. 99)

Dessa forma, a atuação do grupo de formação deveria pautar-se na reflexão sobre a escola que queremos, as concepções educacionais e pedagógicas que estão norteando nossas práticas em sala de aula, para direcioná-las de forma consciente e crítica.

Como reflexo destes estudos iniciais, percebemos que a agressividade e o desrespeito entre as crianças dos primeiros e segundos anos, principalmente, estava interferindo sobremaneira, no desenvolvimento em sala de aula e, pautando-nos também no documentário "As origens da agressão" 2, retomamos

2 Título: Aux origines de l’agression: La violence de l'agneau. Direção: Jean-Pierre Maher. Produção: Jean Gervais, PhD e Richard E. Tremblay, PhD. País: Canadá. Duração: 50 '20". Ano: 2005. Idioma: francês (com legendas em português). 
algumas ações previstas no Projeto Político Pedagógico, como o projeto Roda de leitura e inserimos nesta ação o trabalho com bonecos que tinham alguma deficiência, para os alunos dos primeiros anos e bonecos negros, para os alunos dos segundos anos, com o objetivo de trabalhar as diferenças físicas e étnicas por meio do diálogo entre escola, alunos e familiares sobre o respeito às semelhanças e às diferenças existentes entre os seres humanos, mais precisamente entre o grupo de convívio escolar, seus colegas de turma.

Para fundamentação em sala de aula, os temas selecionados para o ensino de História como identidade, família e grupos sociais foram centrais e fomentadores deste diálogo, porém a questão da afetividade também se colocou como norteadora para esta ação, proporcionando uma intersecção entre a formação intelectual e moral necessária para se construir, de fato, uma educação pública de qualidade.

Outro fator importante considerado em nosso projeto foi a mudança do ensino fundamental de oito anos para o ensino de nove anos, com a entrada de crianças de 6 anos em uma escola sem infraestrutura física adequada para recebê-los, lembrando que nesta faixa etária, as crianças não têm projetos de vida futura, são imediatistas e espontâneas, aprendem brincando e necessitam de tempos e espaços propícios para o lúdico. Por conseguinte, foi necessário rever a organização dos espaços da escola e estabelecer rotinas para o desenvolvimento de um trabalho lúdico-pedagógico, com a criação de uma pequena brinquedoteca, a reforma do parque, melhor ambientação para

as atividades com leitura, além dos recursos audiovisuais e uso de jogos para a alfabetização e o ensino da matemática.

Com as turmas de primeiros anos, o trabalho com os bonecos portadores de deficiências físicas focou a convivência destes com a criança por alguns dias, acompanhados de um livro que retratava histórias de crianças com situação semelhante à do boneco que estava levado para casa e, sua leitura deveria ser feita pelos familiares que, também deveriam realizar o registro das reações e da convivência da criança com o boneco. Este registro era levado para a escola e a criança fazia o relato oral sobre sua vivência com o "pequeno visitante" e sua família, desenvolvendo a oralidade, ao mesmo tempo em que era motivada a expressar os sentimentos gerados pela convivência com um "amigo diferente". 
Os relatos demonstraram que a visita do boneco foi vivenciada de maneira bastante emotiva, cuidadosa e respeitosa e nesta faixa etária não houve problemas de gênero. Contudo esta questão costuma ser uma das fontes de muitos conflitos em sala de aula, expressadas nas pechas de "viado", "bicha" e outras falas das crianças atreladas à sexualidade, mesmo sem saber explicar o significado e a origem deste tipo de provocação. Esta contradição foi discutida nas reuniões de formação dos professores e consideramos que, provavelmente, tais atuações eram repetições do que viam em programas de TV, ouviam em músicas, ou mesmo, vivenciavam nas ruas, mas estavam sendo introjetadas como valores, levando-nos a entender o quanto uma simples ação com bonecos poderia interferir no processo da formação moral dos alunos e de suas famílias, já que todos os meninos participaram do projeto, levando a sacola com um boneco ou boneca, um livro e a pasta de registros.

A temática étnico-racial foi escolhida pelos professores dos segundos anos, porque parte dos conflitos nestas turmas era proveniente do desrespeito e de algumas situações de bullying que estavam surgindo em uma das turmas direcionadas à uma aluna extremamente pobre, como também pela aparente situação de negação das crianças sobre sua origem afrodescendente. A estrutura do projeto era a mesma pensada para os primeiros anos, com a diferença de que para os segundos anos, foi escolhida uma boneca negra chamada "Dandara" - a princesa negra vinda da África- e, por isso, tinha uma vestimenta característica de seu local de origem, assim como sua bagagem (bolsa de viagem, peças de roupas e livros como "Minha princesa africana" de Márcio Vassallo, "Obax" de André Neves, "Lila e o segredo da chuva" de David Conway e Jude Daly, "Bruna e a galinha d Angola" de Gercilga de Almeida e "Menina bonita do laço de fita" de Ana Maria Machado).

A experiência com estas turmas apresentou problemas tanto de gênero como de expressão, acirrada por preconceito racial de parte de poucas famílias e reproduzido por um grupo de alunos em sala de aula. Alguns meninos, já com idade entre 7 e 8 anos se recusaram levar a boneca para casa, outros demonstravam vontade em levá-la, porém não o faziam por vergonha perante outros meninos que diziam que "boneca era coisa de menina e não iriam ficar levando para casa uma sacola enfeitada, com uma boneca dentro". Tivemos 
situações em que a bolsa com a boneca era largada no pátio por algum menino envergonhado. Devido a estes acontecimentos, após discussão com o grupo de professores sobre os problemas que estavam acontecendo, verificamos que não havia tido uma conversa com os pais ou responsáveis pelos alunos como realizado com as turmas de primeiros anos; tínhamos enviado apenas uma carta esclarecendo o início do projeto e foi justamente com esta turma que surgiram manifestações preconceituosas contra a coleguinha da turma. Após detectarmos os problemas, decidimos realizar rodas de conversa com os alunos e a reunião com os pais.

Após as conversas houve mudanças no comportamento dos meninos e o projeto teve continuidade, porém até a data em que foi marcada a reunião com os pais, ocorreu um problema mais sério, quando um dos meninos que havia levado a boneca não a trouxe de volta e, num primeiro momento disse que havia se esquecido, em outro dia disse que havia perdido, para então dizer à professora que sua mãe havia jogado a boneca no lixo. Era claro o constrangimento do aluno sobre o ocorrido, como também a demonstração de que o mesmo não compartilhava com a atitude da mãe. Mais tarde, justamente na reunião com os pais, viemos saber que, na verdade, o pai do aluno, que era pastor ateou fogo nas roupas e jogou a boneca no lixo.

Ao solicitarmos explicações sobre os motivos que levaram o pai a tomar esta atitude, obtivemos a explicação de que houve um acidente e que nada tinha a ver com o fato de a boneca ser negra ou de o filho ter levado uma boneca para casa. Explicamos à família do aluno que o preconceito racial se constitui como crime pela legislação brasileira e que estávamos tentando trabalhar com as crianças a necessidade de construir valores pautados não apenas na legislação, mas principalmente nos princípios éticos que devem reger a convivência em nossa sociedade.

Os pais que compareceram à reunião deram apoio à continuidade do projeto e participaram ativamente, realizando os registros, mas não foram todos. Em nossa percepção, o fato de a boneca ser negra, estar caracterizada com estampas de roupas africanas, ter cabelos trançados provocou a não aceitação de algumas famílias, mesmo as que apresentavam o fenótipo afrodescendente. 
Apesar das dificuldades encontradas na realização desta prática pedagógica, detectamos o crescimento da autoestima da aluna que motivou a realização do "projeto Dandara" e de sua família, assim como mudanças nas relações entre os colegas de turma. A participação e apoio de algumas famílias foram fundamentais não só para a continuidade dos trabalhos, mas para que houvesse maior conhecimento da escola sobre as bases morais com que alguns alunos são educados em suas casas.

Quando relacionamos o resultado da pesquisa realizada com a comunidade, em que $27 \%$ não declararam sua cor, a atitude com relação ao "projeto Dandara" ficou mais esclarecida, evidenciando um grande problema com o qual ainda precisamos trabalhar. Com este projeto e as conversas que tivemos com os pais, pudemos também perceber o distanciamento entre pais e filhos, a falta de espaços nas moradias para as crianças brincarem e o longo tempo que ficam sem a presença dos pais. Com o encerramento do projeto com as turmas de segundos anos e de posse das informações sobre os problemas vivenciados pelas crianças em suas moradias, iniciamos outras ações relacionadas às questões étnico-raciais, dessa vez por meio das brincadeiras.

As professoras regentes de turma, juntamente com a professora de Arte, de Informática, de Sala de Leitura e de Educação Física iniciaram atividades de pesquisas, registros e leituras sobre as brincadeiras de tempos mais remotos, do tempo em que os pais eram crianças e do tempo atual. A partir dos objetivos propostos para a área de História de comparar as condições atuais de existência (alimentação, moradia, proteção familiar, saúde, lazer, vestuário, educação e participação política) dos membros dos grupos de convívio existentes, local e regionalmente, no passado, os alunos juntamente com as professoras elaboraram perguntas sobre as brincadeiras da infância de seus pais e avós, leram livros que abordavam as brincadeiras de crianças africanas e indígenas, confeccionaram materiais para jogos coletivos de origem africana, construíram brinquedos a partir da leitura dos quadros de Ivan Cruz e protagonizaram suas brincadeiras. Entregaram perguntas para os pais responderem e, com auxílio das professoras, tabularam as brincadeiras que mais apareceram nas respostas de seus pais, como amarelinha, pular corda, esconde-esconde, duro ou mole, bolinha de gude, empinar pipas, etc. 
De forma interdisciplinar, o projeto foi se configurando e demonstrando a necessidade da ampliação do diálogo entre as professoras, entre professoras e alunos, alunos e responsáveis, já que o objetivo do projeto não era apenas cognitivo, mas também moral (no sentido da ética) e estético. Buscava maior aproximação entre pais e filhos, criando espaços para que pudessem trocar conversas sobre suas brincadeiras preferidas e exercitá-las juntos; buscando melhorar as inter-relações a partir das brincadeiras em sala de aula e dos jogos cooperativos desenvolvidos nas aulas de Educação Física, trabalhar os diversos conhecimentos como língua portuguesa, matemática, história e geografia; além do respeito às regras dos jogos e brincadeiras, à vez e ao tempo dos colegas, ao mesmo tempo em que se divertiam, também aprendiam.

Vale ressaltar que [...] "A escola deve ser um lugar onde os valores morais são pensados, refletidos, e não meramente impostos ou frutos do hábito. $A$ escola deve ser o lugar onde os alunos desenvolvam a arte do diálogo" (BRASIL, 1997: p. 56).

O protagonismo estudantil era o foco do Projeto Especial de Ação do grupo de professores dos anos finais do ensino fundamental, o que auxiliou a percepção dos professores dos anos iniciais que esta temática também poderia fazer parte do trabalho de formação dos alunos dos $4^{\circ}$ e $5^{\circ}$ anos, já que estavam em uma faixa etária (9 e 10 anos), em que as ações com bonecos, por exemplo, não seriam tão bem recebidas por alunos e familiares. Nesse ínterim, o grêmio estudantil da escola, formado por alunos dos anos finais do ensino fundamental estava organizando conversas com os representantes de sala para a realização de uma assembleia com o objetivo de debater e reorganizar as normas de convívio da escola, apoiados pela gestão escolar.

Estavam exercendo o direito de questionamento e discordâncias, já que não concordavam com algumas regras estabelecidas, como por exemplo, o uso dos uniformes. Tinham propostas sobre a utilização das quadras esportivas durante os intervalos e sobre o uso dos aparelhos de celular, entre outros pontos. Podese dizer que estavam sendo protagonistas. Segundo Rabello (2012: p. 01)

[...] protagonismo é a atuação de adolescentes e jovens, através de uma participação construtiva. Envolvendo-se com questões da própria adolescência/juventude, assim como, com as questões sociais do mundo, da comunidade...Pensando global (O planeta) e 
atuando localmente (em casa, na escola, na comunidade...) o adolescente pode contribuir para assegurar os seus direitos, para a resolução de problemas da sua comunidade, da sua escola...

Em outras palavras, partimos do pressuposto que os alunos de nossa escola devem ser protagonistas de seu aprendizado, transpondo os saberes escolares para a vida cotidiana de forma crítica e consciente.

Com a atuação do grêmio estudantil, o desenvolvimento do projeto de formação sobre Protagonismo estudantil pelos professores do turno vespertino e o diálogo que foi sendo construído entre os dois grupos de formação, entendemos que todas as ações e estudos desenvolvidos com esta temática, convergiam plenamente para os princípios e objetivos das discussões realizadas no Projeto Alfabetização e ética: autonomia discente, autoridade docente e mediação de conflitos.

Ressaltamos ainda, que as discussões e leituras realizadas nos encontros de formação, partiram do entendimento de que o direito à liberdade e à atuação protagonista na escola devem ser pressupostos básicos da relação professor e aluno, seguindo os princípios prescritos no Estatuto da Criança e do AdolescenteECA quanto à liberdade, ao respeito e à dignidade, conforme estabelecido no artigo 16:

Art.16. O direito à liberdade compreende os seguintes aspectos:

I- ir, vir e estar nos logradouros públicos e espaços comunitários, ressalvadas as restrições legais;

II- opinião e expressão;

III- crença e culto religioso;

IV- brincar, praticar esportes e divertir-se;

V- participar da vida familiar e comunitária, sem discriminação;

VI- participar da vida política, na forma da lei;

VII- buscar refúgio, auxílio e orientação.

(ESTATUTO da Criança e do Adolescente, Lei n. 08.069 de $13 / 07 / 1990)$

Muitos aspectos e mitos foram superados quanto ao protagonismo estudantil em nossa escola. Há um grande número de projetos e ações, fruto de estudos e atuações dos profissionais da educação dessa unidade escolar, que favoreceram e incentivaram o papel protagonista do estudante, por meio da interdisciplinaridade e de pesquisas, colocando-os como agentes principais em 
muitas fases dos processos de ensino-aprendizagem e em diversas atuações curriculares.

Contudo, ao pensarmos no dialogismo do processo ensino-aprendizagem e seus agentes (professor e aluno), um aspecto que se colocou como relevante nas discussões de formação foi a necessidade de se desenvolver a visão do professor como mediador da aprendizagem e não apenas de conflitos, o qual abarca inúmeras possibilidades de discussões e de atuações. Para tanto, propusemos aprofundamento nos estudos sobre os processos físicos, sociais, cognitivos e neurológicos da formação do estudante, principalmente dos anos iniciais do ensino fundamental, para contribuir no desenvolvimento de uma atuação docente que propicia a autonomia do estudante, desde os primeiros anos.

Rabello (2012: p.01) afirma em seu artigo sobre o protagonismo juvenil que
A maioria de adolescentes e jovens tem muitas questões, desejos, sonhos... e buscam respostas. Algumas questões vêm da própria fase que estão vivendo, mudanças corporais, primeiras experiências sexuais com um parceiro ou parceira, estimulados pelas primeiras paixões, primeiro amor, primeiras descobertas... Estas questões nem sempre encontram respostas, pois a escola, a família, a sociedade não estão preparadas para isso. Outras questões são impostas pela desigualdade social provocando a exclusão de uma grande parcela desta população. A estes e estas falta escola pública de qualidade, o atendimento à saúde, a segurança, o lazer.

Esta afirmação nos levou a refletir sobre o exercício de escuta, de mediação, de interlocução das crianças com o mundo adulto de forma articulada, ética e verdadeira. Dessa forma a escola poderia se tornar um dos lócus principais para que crianças e adolescentes consigam desenvolver formas de atuação e participação protagonista e transformadora de uma determinada condição social, cultural e política. Entendemos também que a escola é um espaço de contradições onde a reprodução destas condições pode se consolidar como também se transformar, dependendo da concepção política de seu projeto pedagógico. Por isso, a opção por um projeto de formação de professor mediador a partir das concepções éticas foi uma opção política que pretendia se contrapor às condições de reprodução de todo tipo de desigualdade e violência contra o outro. 
O plano de trabalho da área de História dos $4^{\circ}$ e $5^{\circ}$ anos pautou-se nas expectativas de aprendizagem, conforme currículo em vigência no município de São Paulo que propunha os seguintes objetivos:

- Construir a sua identidade como sujeito individual e coletivo;

- Respeitar as diversidades socioculturais, políticas, étnico-raciais e de gênero que compõem a sociedade atual;

- Desenvolver a noção de pertencimento, a partir das semelhanças e diferenças dos grupos de convívio de que participa;

- Conhecer a história da cidade usando diferentes fontes: escritas, orais, iconográficas, musicais e estudo do meio;

- Identificar na história da cidade lutas sociais da população em prol de melhores condições de vida;

- Identificar os principais momentos da história da cidade de São Paulo e as ações dos sujeitos que atuaram: portugueses, indígenas e africanos;

- Identificar as diferenças sociais e de participação nas ações políticas, dos grupos e classes sociais que convivem na cidade;

- Conhecer e registrar com marcadores de tempo as formas de governo da cidade de São Paulo e do Brasil em diferentes momentos: Colônia, Império e República;

- Relacionar a diversidade cultural da população do bairro, com a população da cidade de São Paulo e do Brasil, identificando e valorizando as diferenças de costumes dos grupos sociais e étnicos;

- Organizar a história da cidade e sua relação com a história brasileira.

Estes objetivos foram utilizados para o desenvolvimento de algumas ações com alunos dos $4^{\circ}$ e $5^{\circ}$ anos, como a participação e organização de assembleias para reorganizar as normas de convívio da escola, com a ajuda do Grêmio Estudantil formado pelos alunos dos anos finais do ensino fundamental, a pesquisa sobre as condições sociais e ambientais do entorno da escola para identificação dos problemas que necessitam de soluções políticas e de atuação de cada um.

Para discutir as normas da escola, os professores realizaram rodas de conversa abordando a necessidade de eleger os representantes de sala, quais suas funções, para em seguida organizar pequenas assembleias com participação 
do grêmio estudantil, com o objetivo de discutir a organização escolar e as normas de convívio, denominadas na escola como "combinados". Para o desenvolvimento destas ações, os professores trabalharam com os alunos as concepções de individualidade e coletividade, direitos e deveres, individualismo e cidadania, participação política e democracia, destacando aspectos sobre o respeito às diferenças de opiniões e a necessidade de se ter um consenso sobre os novos "combinados" da escola. O trabalho partiu de uma questão mais reflexiva e ampla que também estava sendo feita no grupo de formação dos professores: Que escola temos e que escola queremos?

O trabalho ocorreu primeiro em sala de aula, para depois reunir todos os $4^{\circ}$ anos no pátio da escola, todos os $5^{\circ}$ anos, e por fim uma assembleia geral em que debateram e votaram ponto a ponto dos combinados que foram elaborados nas rodas de conversa em sala de aula.

O processo não foi fácil e nem tranquilo, porque não estavam acostumados a participar de discussões com todos os alunos reunidos, mas verificamos que o sentimento de pertencimento ao espaço escolar foi ampliado, sentiram-se responsáveis pela escola, ao mesmo tempo em que passaram a ser críticos quanto ao cumprimento dos "combinados", seja pelos colegas, seja pela equipe gestora. Fato este demonstrado pela carta elaborada por uma turma de $5^{0}$ ano, cobrando maior atuação da gestão escolar em relação a alguns pontos dos "combinados" que, segundo esta turma, não estavam sendo cumpridos por todos os alunos e nem pela gestão.

Durante as reuniões de formação, os professores trocavam as experiências vivenciadas pelas turmas durante o desenvolvimento dos projetos e, de acordo com estes professores, foi possível perceber que a partir do momento em que os alunos participaram da organização das normas de convívio, houve maior incorporação das mesmas e entenderam que não poderia haver privilégios para uns em detrimento dos colegas e que é esta a forma que a sociedade encontra para se organizar.

Como continuidade do trabalho de formação de alunos protagonistas, autônomos e conhecedores de sua realidade de vida, o projeto vivenciado pelas turmas de $5^{\circ}$ anos levou-os para fora da escola, para o bairro onde se situa a escola e a moradia de todos eles. Era importante que passassem a conhecer a 
história de seu bairro e de sua cidade, para identificarem características de sua comunidade, problemas vivenciados e criados por esta comunidade, a fim de relacionarem com suas próprias histórias e trajetórias.

Foram realizadas três saídas pelo bairro, todas organizadas previamente com as professoras regentes de sala, professores de Arte, Informática e Educação Física. Realizaram um estudo do meio, destacando os aspectos sociais como problemas no transporte, moradia e saúde e, ambientais como o lixo nas ruas, praças e córregos da região, a ausência de coleta de lixo em alguns pontos do bairro, as diferenças de moradia com condomínios fechados de um lado, prédios populares - Cingapura - e favelas de outro. Fizeram coleta de tipos de lixo mais encontrados, elaboraram croquis de percursos, realizaram entrevistas com moradores, pesquisaram a história do bairro e acrescentaram as histórias que conheciam, principalmente relacionadas ao uso de drogas por adolescentes e jovens, registraram em desenhos e fotografias, discutiram em sala de aula os problemas encontrados. Participaram de outro estudo do meio, em um parque mais distante do bairro, que realizava atividades de reciclagem, hortas e relacionaram com a pequena horta que encontraram em uma praça mantida por um morador do bairro que lutava sozinho pela preservação da limpeza neste espaço.

E por fim, sentiram a necessidade de fazer algo com tudo o que viram e observaram. Juntamente com as professoras, montaram painéis explicativos para apresentação na mostra cultural da escola, assim mais pessoas poderiam partilhar da vivência que tiveram e dos conhecimentos que adquiriram e poderiam assinar o abaixo-assinado que elaboraram para encaminhar à subprefeitura, solicitando maior atenção com a limpeza pública e melhorias no atendimento da Unidade Básica de Saúde do bairro.

Todas as ações pedagógicas pensadas a partir do currículo de História foram permeadas pelas discussões, estudos e trocas de experiências entre professores no Projeto Especial de Ação, a partir dos princípios da ética relativos à convivência humana, ao respeito à diversidade de gênero, étnica e social, ao protagonismo estudantil, à autoridade docente encontrada no papel de professor mediador e à democracia. 


\section{Considerações finais}

O tema transversal sobre a Ética parte do pressuposto de que todas as áreas de conhecimento exercitem o trabalho de formação ética dos alunos e não apenas uma área, porém esta transversalidade não ocorre nas escolas sem um eixo impulsionador que, via de regra, acaba sendo a disciplina de História.

Por meio dos objetivos propostos para esta área de conhecimento, as práticas pedagógicas descritas neste artigo foram planejadas, discutidas e revistas dentro do projeto de formação dos professores que propiciou a fundamentação teórico-prática e reflexiva centrada na busca de respostas para as questões "o que precisa ser preservado em minha ação pedagógica? Afinal de contas, a que ela se presta? Que mundo se vislumbra aqui e agora? Que escola temos e que escola queremos?".

Constatamos que o ciclo de alfabetização (anos iniciais do Ensino Fundamental) pode e deve desenvolver práticas que incentivem a formação ética das crianças por meio de temas relativos aos valores morais como respeito a si próprio e ao outro, respeito às diferenças, diálogo, convivência e que todas as áreas de conhecimento podem e devem se envolver com esta formação.

No processo de desenvolvimento das práticas pedagógicas, nos aproximamos de algumas respostas e fortalecemos as premissas estabelecidas em nosso Projeto Político Pedagógico sobre a necessidade de incentivar a formação de um aluno autônomo, protagonista e crítico desde os primeiros anos da alfabetização e, para isto, nossa ação pedagógica precisa refletir estes princípios, possibilitando a formação de sujeitos que possam contribuir para as transformações sociais, políticas e econômicas que se fazem necessárias em nossa sociedade.

\section{Referências}

AQUINO, J. G. Do cotidiano escolar: ensaios sobre a ética e seus avessos. São Paulo: Summus, 2000. 
BRASIL. Estatuto da criança e do adolescente- ECA. Lei no 8.069 de 13/07/1990. Disponível no site http://www.planalto.gov.br/ccivil 03/leis/l8069.htm . Acesso em 03/03/2014

Secretaria de Educação Fundamental. Parâmetros curriculares nacionais: apresentação dos temas transversais, ética. Secretaria de Educação Fundamental. - Brasília: MEC/SEF, 1997. Disponível no site http://portal.mec.gov.br/seb/arquivos/pdf/livro081.pdf Acesso em Nov/2014.

. Ensino Fundamental de nove anos- orientações para a inclusão da criança de seis anos de idade. Brasília, MEC, 2007.

FAZENDA, I. (Org.). GODOY, H. P. Interdisciplinaridade: pensar, pesquisar e intervir. São Paulo: Cortez, 2014.

HERNÁNDEZ, F.; VENTURA, M. A organização do currículo por projetos de trabalho: o conhecimento é um caleidoscópio. Porto Alegre, Artmed, 1998.

INSTITUTO HUMANITAS USININOS. Nova classe média: um discurso economicista. Entrevista especial com Jessé de Souza. Jan.2013. Disponível no site http://www.ihu.unisinos.br/entrevistas/516686-nova-classe-media-umdiscurso-economicista-entrevista-especial-com-jesse-de-souza Acesso em 03/03/2015.

RABELLO, M. E. D. L. O que é protagonismo juvenil? Disponível no site http://www.cedeca.org.br/conteudo/noticia/arquivo/39DA691A-FD4E-D1193DAE60914B0999AE.pdf- Acesso em 15/02/2014

TAILLE, Y.; SOUZA, L. S.de; VIZIOLI, L. Ética e educação: uma revisão da literatura educacional de 1990 a 2003. Educação e Pesquisa, São Paulo, v.30, n.1, p. 91-108, jan./abr. 2004. Disponível no site http://www.scielo.br/pdf/ep/v30n1/a06v30n1.pdf . Acesso em 14/03/2015.

YACCOUB, H. A chamada "nova classe média": cultura material, inclusão e distinção social. Rio de Janeiro. Universidade Fluminense do Brasil, 2011.

Disponível no site http://www.scielo.br/pdf/ha/v17n36/v17n36a09.pdF . Acesso em 15/02/2015 